\title{
Title: Influence of Acidosis on Cardiotonic Effects of Colforsin and Epinephrine: A Dose-Response Study
}

\section{Authors:}

Keiichi Hagiya, MD.

- Affiliation: Department of Anesthesiology, University of Tsukuba

- E mail: hagiya916@yahoo.co.jp

- Attestation: Study design, Conduct of the study, Data collection, Data analysis, and Manuscript preparation

Hiroshi Takahashi, MD.

- Affiliation: Department of Anesthesiology, University of Tsukuba

- E mail: hirolin@md.tsukuba.ac.jp

- Attestation: Data collection, and Data analysis

Yumi Isaka, Chief Technical Official

- Affiliation: Technical Service Office for Medical Sciences, University of Tsukuba

- E mail: yumii@md.tsukuba.ac.jp

- Attestation: Data collection 
Shinichi Inomata, MD.

- Affiliation: Department of Anesthesiology, University of Tsukuba

- E mail: inomatas@md.tsukuba.ac.jp

- Attestation: Data analysis, and Manuscript preparation

Makoto Tanaka, MD.

- Affiliation: Department of Anesthesiology, University of Tsukuba

- E mail: mtanaka@md.tsukuba.ac.jp

- Attestation: Study design, Data analysis, and Manuscript preparation

Corresponding Author: Keiichi Hagiya

Mailing address: Department of Anesthesiology, University of Tsukuba, Tsukuba City, Ibaraki 305-8575, Japan

Tel: $+81-29-853-3285$

Fax: $+81-29-853-3092$

E-mail: hagiya916@yahoo.co.jp

Conflict of interest: None of the authors or relatives in the third degree of kinship, department or institution had ever received financial gain such as direct monetary benefits, investments, stocks, funds or honoraria from Nippon Kayaku Co., Ltd, which kindly provided 
colforsin alone. In addition, none ever had a consulting or lecturing relationship with Nippon Kayaku Co., Ltd.

\section{Acknowledgements}

We thank Tōru Nanmoku for assistance with measuring levels of cyclic adenosine monophosphate. 


\begin{abstract}
Objective: Acidosis produces a negative inotropic effect on cardiac muscle against which catecholamines and phosphodiesterase III inhibitors have limited therapeutic effects. This study was designed to evaluate effects of colforsin, which directly activates adenylate cyclase without beta-receptor activation, in isolated Langendorff rat hearts in a $\mathrm{pH}-$ and concentration-dependent manner.
\end{abstract}

Design: Experimental animal study.

Setting: A university laboratory.

Participants: Sprague-Dawley rats.

Interventions: Hearts were isolated and perfused with HEPES-Tyrode solution (pH 7.4) in the Langendorff preparation. The hearts were randomly assigned to control ( $\mathrm{pH}$ 7.4), mild ( $\mathrm{pH}$ 7.0), and severe ( $\mathrm{pH}$ 6.6) acidosis groups $(\mathrm{n}=8$ each) and were continuously perfused with $10^{-7} \mathrm{M}, 10^{-6} \mathrm{M}$, and $10^{-5} \mathrm{M}$ colforsin.

Measurements and Main Results: Left ventricular maximum rate of increase (LV $\mathrm{dP} / \mathrm{dtmax}$ ) were determined, and the concentration-response relationship were evaluated at each pH. Colforsin at $10^{-6} \mathrm{M}$ increased $\mathrm{LV} \mathrm{dP} / \mathrm{dtmax}$ from $2592 \pm 557$ to $5189 \pm 721$ $\mathrm{mmHg} / \mathrm{s}(P<0.001)$ and from $1942 \pm 325$ to $3399 \pm 608 \mathrm{mmHg} / \mathrm{s}(P<0.001)$ in the control and mild acidosis groups, respectively, while $10^{-5} \mathrm{M}$ colforsin significantly increased LV $\mathrm{dP} / \mathrm{dtmax}$ even in the severe acidosis group. No significant difference was seen in LV $\mathrm{dP} / \mathrm{dtmax}$ among the three groups after $10^{-5} \mathrm{M}$ colforsin infusion.

Conclusion: In contrast with catecholamines and other inodilators, colforsin at high concentration restores diminished cardiac contractility against severe acidosis to the extent similar to the physiological $\mathrm{pH}$. 
Keywords: acidosis, adenylate cyclase, colforsin, cyclic AMP 


\section{Introduction}

Acidosis produces a negative inotropic effect on cardiac muscle ${ }^{1-6}$ and diminishes the inotropic effects of catecholamines ${ }^{7-11}$ and of phosphodiesterase isozyme III (PDE III) inhibitor $^{12}$. The inotropic effect of catecholamines and PDE III inhibitor results mainly from increased concentrations of intracellular cyclic adenosine monophosphate (cAMP) generated by stimulating beta-adrenergic receptors and by inhibiting PDE III, respectively. Although the cause of the diminished myocardial responses to catecholamines has not been completely elucidated, decreased cAMP production as a result of depressed adenylate cyclase activity ${ }^{7}$, decreased numbers of beta-adrenergic receptors ${ }^{7,8}$, decreased affinity for agonists ${ }^{9}$, decreased Ca2+ sensitivity of myofilaments ${ }^{1}$, and reducing opening of the sarcoplasmic reticulum Ca2+ release channel ${ }^{13}$ might be involved.

Colforsin (NKH477;6-(3-dimethyl-aminopropionyl) forskolin hydrochloride) is a water-soluble forskolin derivative that increases cardiac output and the maximum rate of increase in left ventricular pressure ( $\mathrm{LV} \mathrm{dP/dtmax)} \mathrm{in} \mathrm{patients} \mathrm{with} \mathrm{left} \mathrm{ventricular} \mathrm{systolic}$ dysfunction ${ }^{14}$. Colforsin exerts positive inotropic action by directly activating adenylate cyclase and might therefore increase heart contractility in acidosis. However, the influence of acidosis on inotropic effects of colforsin has not been evaluated.

We hypothesized that colforsin augments the contractility of isolated rat heart as a result of concomitant increase in cAMP in severe acidosis. Accordingly, this investigation was designed to evaluate cardiotonic effects of colforsin in a concentration-dependent manner at various degrees of acidosis, and determined cAMP concentrations to elucidate its possible contribution in an isolated rat heart preparation. 


\section{Methods}

Experimental animals

The Animal Research Committee at University of Tsukuba approved this study. Nineweek-old male Sprague-Dawley rats (Japan SLC, Shizuoka, Japan), weighing 280 to 360 g, were housed in stainless-steel cages and maintained at $23.5 \pm 2.5^{\circ} \mathrm{C}, 52.5 \pm 12.5 \%$ humidity and a 14-h light and 10-h dark cycle with free access to food and water ad libitum.

Langendorff heart preparation

One hundred and two male Sprague-Dawley rats aged 10 weeks were first assigned to either experiment 1 (hemodynamic measurements, $n=66$ ) or experiment 2 (cAMP measurement, $n=36$ ). In both experiments, rat hearts were similarly prepared and perfused with Langendorff apparatus. They were anesthetized with an intraperitoneal injection of pentobarbital sodium ( $80 \mathrm{mg} / \mathrm{kg})$. The hearts were isolated via thoracotomy and the aorta was connected to a Langendorff apparatus (RADNOTI LLC, Monrovia, CA, USA). The hearts were perfused at constant flow of approximately $10 \mathrm{~mL} / \mathrm{min}$ for several minutes and then were gravity perfused at a constant pressure with HEPES-Tyrode solution $(\mathrm{pH}=7.4)$ at 37.0 $\pm 0.3^{\circ} \mathrm{C}$ in a thermostatically controlled recirculating water bath (Harvard Apparatus Ltd, Edinbridge, Kent, UK). The HEPES-Tyrode solution comprised (mM) 137.0 NaCl, 6.0 KCl, 1.0 $\mathrm{MgCl}_{2}-6 \mathrm{H}_{2} \mathrm{O}, 1.8 \mathrm{CaCl}_{2}-2 \mathrm{H}_{2} \mathrm{O}$, 5.5 Glucose, 10 HEPES, and $\mathrm{NaOH}$ titrated to the required $\mathrm{pH}$, and bubbled with $100 \% \mathrm{O}_{2}$. A fluid-filled balloon was inserted into the left ventricle via an incision in the left atrium and inflated at 2 to $5 \mathrm{mmHg}$ of left ventricular enddiastolic pressure during the initial stabilization period. After stabilization and baseline measurements, we measured coronary perfusion flow (CPF), coronary perfusion pressure (CPP), and left ventricular pressure (LVP). Measurements of CPP were made using a 
pressure transducer at the aortic level. The LV dP/dtmax, determined by differentiating LVP waveform, was computed using AcqKnowledge ${ }^{\mathrm{TM}}$ software (BIOPAC Systems, Goleta, CA, USA). All pressure data are digitized using a 16-bit analog-digital converter, stored at a sampling rate of $1000 \mathrm{~Hz}$ in a computer, and subsequently analyzed offline. For real-time smoothing transformation of LVP, dP/dtmax and HR data, smoothing factor of three was used in our study, ie. an average was computed as the mean of three adjacent data of the moving "window" before moving on to the next data set. Ten values of CPP, LVP and LV $\mathrm{dP} / \mathrm{dtmax}$ in each measurement period were averaged and reported as a representative of each heart at each $\mathrm{pH}$ and at each colforsin or adrenaline concentration. CPF was measured by collecting the perfusate draining from the perfused heart for a minute.

\section{Experiment 1 (Figure 1)}

Sixty-six rats were first assigned to either colforsin study $(n=24)$, adrenaline study (n = 24), or vehicle control $(\mathrm{n}=18)$, and then, subsequently randomized to the control $(\mathrm{pH}=$ 7.4), mild acidosis ( $\mathrm{pH}=7.0)$, and severe acidosis $(\mathrm{pH}=6.6)$ groups $(\mathrm{n}=8$ each for colforsin and adrenaline study, $\mathrm{n}=6$ each for vehicle control). After 10 minutes of stabilization using HEPES-Tyrode solution of $\mathrm{pH} 7.4$, LVP, CPP, and CPF were determined, and then the HEPES-Tyrode solution adjusted to the appropriate $\mathrm{pH}$ for each group was perfused continuously throughout the experiment. Ten minutes after the $\mathrm{pH}$ change, Langendorff hearts were continuously perfused with constant pressure with $10^{-7} \mathrm{M}, 10^{-6} \mathrm{M}$, and $10^{-5} \mathrm{M}$ colforsin or with $10^{-8} \mathrm{M}, 10^{-7} \mathrm{M}$, and $10^{-6} \mathrm{M}$ adrenaline for 10 minutes each. We measured LVP, CPP, and CPF 10 minutes after the $\mathrm{pH}$ change and at the end of each concentration of colforsin or adrenaline for 10 minutes. This time interval represented a peak contractile effect for all concentrations of cardiotonic drugs in our experiment (Figure 2). The concentration- 
response relationships between these variables and colforsin $\left(10^{-7}\right.$ to $\left.10^{-5} \mathrm{M}\right)$ or adrenaline $\left(10^{-8}\right.$ to $\left.10^{-6} \mathrm{M}\right)$ were determined at each $\mathrm{pH}$.

\section{Experiment 2 (Figure 1)}

The remaining 36 rats were randomly assigned to the following six groups: with $10^{-5}$ $\mathrm{M}$ colforsin at $\mathrm{pH} 7.4$ and at $\mathrm{pH}$ 6.6, with $10^{-6} \mathrm{M}$ adrenaline at $\mathrm{pH} 7.4$ and at $\mathrm{pH}$ 6.6, and without cardiotonic drugs at $\mathrm{pH} 7.4$ and $\mathrm{pH} 6.6$ ( $\mathrm{n}=6$ each). Ten minutes after connecting the Langendorff apparatus, hearts were perfused with $\mathrm{pH} 7.4$ HEPES-Tyrode solution for 10 minutes, and then, at either $\mathrm{pH} 7.4$ or 6.6 throughout the experiment. The colforsin and adrenaline groups of hearts at both $\mathrm{pH}$ were continuously infused with colforsin $\left(10^{-7}, 10^{-6}\right.$, and $\left.10^{-5} \mathrm{M}\right)$ and adrenaline $\left(10^{-8}, 10^{-7}\right.$, and $\left.10^{-6} \mathrm{M}\right)$ for 10 minutes in a similar manner to that of the experiment 1 , and then, the hearts were immediately frozen in liquid nitrogen $\left(-45^{\circ} \mathrm{C}\right)$. Vehicle control groups received 30 minutes of saline infusion instead of colforsin or adrenaline at both $\mathrm{pH}$, and then hearts were similarly frozen. The left ventricular muscles were separated, disrupted in $5 \mathrm{ml}$ of $5 \%$ trichloroacetic acid using a digital homogenizer (Iuchi, Osaka, Japan) and centrifuged at 2,000 $\times \mathrm{g}$ for 15 minutes at $4^{\circ} \mathrm{C}$. The supernatants were washed four times with $5 \mathrm{ml}$ of diethyl ether saturated with water. The upper ether layer was discarded after each wash. The remaining aqueous extract was dried under a stream of nitrogen at $60^{\circ} \mathrm{C}$. The dried extracts were dissolved in $300 \mu \mathrm{l}$ of RPMI 1640 medium. Concentrations of cAMP were quantified using a dextran-coated charcoal radioimmunoassay (SRL, Inc., Tokyo, Japan). The sensitivity of this method (average binding ratio of 80 $\mathrm{pmol} / \mathrm{ml}$ standard solution minus average binding ratio of $0 \mathrm{pmol} / \mathrm{ml}$ standard solution) is over $38 \%$, detection limit is $0.62 \mathrm{pmol} / \mathrm{ml}$, and coefficient of variation is 3.1 to $4.9 \%$. 
Chemicals

Sodium pentobarbital (Nembutal injection), a product of Abbott Laboratories (Abbott Park, Chicago, IL, USA) was purchased from Dainippon Sumitomo Pharmaceutical Co. (Osaka, Japan), and adrenaline was purchased from Daiichi Sankyo Co., Ltd. (Tokyo, Japan). Colforsin was kindly provided from Nippon Kayaku, Co., Ltd.

Statistics

All data are expressed as mean \pm SD. Statistical differences in LV dP/dtmax and CPF were assessed using repeated-measures ANOVA followed by unpaired t-test with Scheffé's test to adjust for multiple comparisons, with a probability level of $P<0.05$ being significant. Unpaired $t$-test was also used for comparison between variables with cardiotonic drugs at each $\mathrm{pH}$ and time- (vehicle-) control values. Concentrations of cAMP between two pH's were compared using unpaired $t$-test with a probability level of $P<0.05$ being significant. All data were analyzed using Stat-View software (SAS Inc., Cary, NC, USA). 


\section{Results}

The CPP values remained stable from 62 to $63 \mathrm{mmHg}$ throughout the experiment in all groups. The $\mathrm{pH}$ change decreased HR in the severe acidosis group from $200 \pm 34$ to $108 \pm$ 24 bpm $(P<0.001)$, but not in the control and mild acidosis groups (from $218 \pm 38$ to $213 \pm$ $43 \mathrm{bpm}$, and from $194 \pm 19$ to $171 \pm 28 \mathrm{bpm}$, respectively). Colforsin at $10^{-5} \mathrm{M}$ increased $\mathrm{HR}$ in the severe acidosis, mild acidosis, and control groups (to $215 \pm 39$, $235 \pm 31$, and $269 \pm 26$ bpm, respectively), but did not result in any significant differences among the three groups at $10^{-5} \mathrm{M}$ colforsin. Similarly, adrenaline $10^{-6} \mathrm{M}$ increased $\mathrm{HR}$ in the severe acidosis, mild acidosis, and control groups (from $110 \pm 18$ to $173 \pm 24$, from $172 \pm 26$ to $235 \pm 35$, and from $163 \pm 16$ to $231 \pm 45 \mathrm{bpm}$, respectively), but did not result in any significant differences among the three groups.

Mild (pH 7.0) and severe ( $\mathrm{pH}$ 6.6) acidosis groups developed significantly decreased LV dP/dtmax compared with pre-pH change (Figures 3). LV dP/dtmax at each $\mathrm{pH}$ were essentially unchanged without colforsin or adrenaline throughout the experiment. Therefore, LV dP/dtmax with colforsin or adrenaline at each concentration was also compared with these time control values without cardiotonic drugs. Colforsin $\left(10^{-6} \mathrm{M}\right.$ and $\left.10^{-5} \mathrm{M}\right)$ significantly increased $\mathrm{LV} \mathrm{dP/dtmax} \mathrm{compared} \mathrm{with} \mathrm{the} \mathrm{post-pH} \mathrm{change} \mathrm{in} \mathrm{all} \mathrm{the} \mathrm{groups.}$ Although $\mathrm{LV} \mathrm{dP} / \mathrm{dtmax}$ values in the mild and severe acidosis groups at $10^{-6} \mathrm{M}$ colforsin were significantly less than those of the control group, such difference dissipates at $10^{-5} \mathrm{M}$ colforsin (Figure 4). The pH change also decreased CPF significantly in the severe acidosis group, but not in the mild acidosis group (Figure 5). CPF remained unchanged for the entire experiment after $\mathrm{pH}$ change without colforsin or adrenaline (time control, data not shown). All tested concentrations of colforsin increased CPF compared with the post $\mathrm{pH}$ change in the all the groups (Figure 5). At colforsin at $10^{-5} \mathrm{M}$, no significant difference was found in LV $\mathrm{dP} / \mathrm{dtmax}$, CPF or HR among the three groups. 
Adrenaline $10^{-7} \mathrm{M}$ and $10^{-6} \mathrm{M}$ significantly increased $\mathrm{LV} \mathrm{dP} / \mathrm{dtmax}$ compared with the post-pH change in the control and mild acidosis groups (Figure 6). In the severe acidosis group, $\mathrm{LV} \mathrm{dP} / \mathrm{dtmax}$ increased significantly only by $10^{-6} \mathrm{M}$ adrenaline. In contrast to colforsin, adrenaline at its maximum dose $\left(10^{-6} \mathrm{M}\right)$ did not restore $\mathrm{LV} \mathrm{dP} / \mathrm{dtmax}$ to the level similar to physiological $\mathrm{pH}$ (Figure 6). The $\mathrm{pH}$ change also decreased CPF significantly in the severe acidosis group, but not in the mild acidosis group (Figure 7). CPF increased significantly at all tested concentrations of adrenaline in the control and mild acidosis groups. In the severe acidosis group, however, CPF remained unchanged at all concentrations studied.

The hemodynamic status of all groups in the cAMP study (experiment 2) was similar to those of the experiment 1 (data not shown). Severe acidosis decreased the amount of cAMP, whereas colforsin $10^{-5} \mathrm{M}$ increased cAMP concentrations to the level similar to that of $\mathrm{pH} 7.4$ (Figure 8). On the other hand, even though adrenaline $10^{-6} \mathrm{M}$ increased cAMP contents compared with no adrenaline at both $\mathrm{pH} 7.4$ and 6.6, that of $\mathrm{pH} 6.6$ was significantle less than that of $\mathrm{pH} 7.4$. 


\section{Discussion}

This is the first study which demonstrated concentration-dependent changes in cardiotonic effects by colforsin on a background of various degrees of acidosis. The present findings show that colforsin restores diminished cardiac contractility by severe acidosis to the level similar to the physiologic $\mathrm{pH}$ in isolated rat hearts, which has never been reported in the past using catecholamines or PDE III inhibitors. Indeed, maximum cardiotonic response even with the largest dose of adrenaline could not be attained in our study. These results suggest greater relative inotropic potency of colforsin in the acidotic environment. Therefore, colforsin could be theoretically useful in clinical situations where other inotropic drugs have failed to restore contractility, when acidosis is rigid and severe. However, further in vivo studies are warranted to confirm its cardiotonic effects under various degrees of acidosis using clinically relevant concentrations of colforsin.

One may argue that the maximum contractile response was not attained using $10^{-6} \mathrm{M}$ adrenaline and larger adrenaline dose might have produced cardiotonic effects to an extent similar to that at physiological $\mathrm{pH}$, as seen with the largest concentration of colforsin. In our pilot study ${ }^{15}$, however, $10^{-5} \mathrm{M}$ adrenaline resulted in frequent occurrence of ventricular ectopic contractions in more than half of the preparations, and stable hemodynamics could not be obtained for further analysis of $\mathrm{LV} \mathrm{dP} / \mathrm{dtmax}$. On the other hand, unlike other cardiotonic drugs including catecholamines and PDE III inhibitors, colforsin has been shown to suppress digitalis- and adrenaline-induced arrhythmia in canine model ${ }^{16}$, and indeed, ventricular arrhythmia was not observed in our preparation even with the largest colforsin concentration. Although colforsin has been clinically available since 1999, similar hemodynamic profile as an inodilator to PDE III inhibitors and relatively longer half-life $\left(\mathrm{t}_{1 / 2 \beta}\right.$ $=1.9 \pm 0.7$ hour, $\mathrm{t}_{1 / 2 \gamma}=95.3 \pm 15.2$ hour) in actual surgical patients hampered its clinical popularity ${ }^{17}$. In in vivo canine preparation, colforsin has been reported to increase myocardial Page 13 of 23 
oxygen consumption ${ }^{18}$, while small dose of colforsin appears to produce improved cardiac performance without increases in myocardial oxygen demand in humans after coronary artery bypass grafting. More importantly, its anti-arrhythmogenic property together with restored cardiotonic effect during severe acidosis suggests its superiority when use of other inotropic agents is limited for unsatisfactory inotropic effects due to severe acidosis or arrhythmogenic property $^{19}$.

Colforsin at $10^{-7}$ and $10^{-6} \mathrm{M}$ failed to demonstrate improved cardiac performance at $\mathrm{pH} 6.6$ to a level equivalent to that of $\mathrm{pH}$ 7.4. In contrast, $10^{-5} \mathrm{M}$ colforsin restored $\mathrm{LV}$ $\mathrm{dP} / \mathrm{dtmax}$ even at $\mathrm{pH}$ 6.6. These results indicate that the inotropic effects of colforsin are decreased in the severely acidotic heart, but irrespective of catecholamines and PDE III inhibitors increasing colforsin concentration negates the deleterious effect of acidosis on its cardiotonic effect. Acidosis depresses cardiac performance ${ }^{1-6}$ and the inotropic effect of catecholamines $^{7-11}$. Several factors are considered to play a role in diminished myocardial responses to catecholamines, such as reduction in the numbers of beta-adrenergic receptors ${ }^{7,8}$, reduced affinity for agonists ${ }^{9}$, depressed adenylate cyclase activity ${ }^{7}$, decreased cAMP production $^{7}$, inhibition of calcium ion exchange ${ }^{20}$, and decreased affinity of calcium ions for myofilaments $^{11,21,22}$. Decreased cAMP turnover is also important in the deleterious effect of acidosis on pharmacologic action of milrinone ${ }^{12}$. Because colforsin exerts positive inotropic action by directly activating adenylate cyclase, a reduction in the numbers and affinity of beta-adrenergic receptors would not have affected the inotropic property of colforsin. Although changing the $\mathrm{pH}$ from 7.4 to 6.6 decreased the amount of cAMP, $10^{-5} \mathrm{M}$ colforsin restored cAMP concentration at $\mathrm{pH} 6.6$ to that similar to $\mathrm{pH} 7.4$ in the present study, suggesting that an increase in myocardial cAMP concentration may, in part, account for the inotropic effects of colforsin in severe acidosis. Further studies are required to understand the 
more precise mechanisms of restored inotropic effect of colforsin, such as calcium ion exchange and calcium affinity to myofilaments.

In our study, cardiotonic effects of colforsin under mild acidosis appear to be augmented at a concentration-dependent manner, though to a less extent, than those at physiological $\mathrm{pH}$. Previous literature showed that mechanical function to isoproterenol during acidosis ( $\mathrm{pH}$ 6.8) was not different from control condition ( $\mathrm{pH} 7.4$ ) in isolated arterially perfused heart of the newborn rabbits ${ }^{7}$. Similarly, decreasing cellular $\mathrm{pH}$ from 7.4 to 6.8 resulted in a decline in contractile amplitude to isoproterenol only by $20 \%$ in cultured myocardial cells from chick embryo ventricle ${ }^{8}$. In a canine in vivo preparation, on the other hand, significant and profound depressions of LV dP/dtmax in response to 2 and $5 \mu \mathrm{g} / \mathrm{kg} / \mathrm{min}$ of milrinone under mild acidosis ( $\mathrm{pH}$ 7.0) compared with the physiological $\mathrm{pH}$ were observed $^{12}$. These discrepant observations of myocardial contractile responses to various cardiotonic drugs under relatively mild acidotic condition may arise from the differences in animals, drugs, as well as in experimental models.

We examined how acidosis affects the cardiotonic effect of colforsin up to $10^{-5} \mathrm{M}$, which is approximately 100 -fold greater than the clinically applied concentration ${ }^{23}$. Since the isolated heart model was used in this investigation, effect of colforsin on blood pressure and the vascular system could not be evaluated. Colforsin stimulates mainly cardiac adenylyl cyclase, and in part, other tissue adenylyl cyclases (lung, brain, and kidney) type II, III and $\mathrm{V}^{24}$. Colforsin produces systemic and pulmonary vasodilation and increases renal blood flow $^{25,26}$. These factors may contribute to decreasing afterload and preload in vivo, which may ultimately lead to hypotension. In addition, chronic exposure to a high concentration of colforsin might cause hypertrophy of the heart, myocardial fibrosis, and myocardial degeneration ${ }^{27-29}$. Therefore, further studies using an in vivo model are warranted to evaluate 
the relationships between acidosis and colforsin in a situation similar to the actual clinical environment as well as short-term toxicity of colforsin before a large dose is recommended in clinical situations.

Study limitations include significant decreases in CPF during acidosis, and thus, the change in hemodynamics might have involved an effect of the decreased CPF, especially with adrenaline. However, colforsin $10^{-7}$ and $10^{-6} \mathrm{M}$ in the severe acidosis resulted in significant increases in CPF with limited effects on LV dP/dtmax, suggesting that CPF was not a sole mechanism to explain depressed cardiac performance in severe acidosis. Secondly, we did not enzymatically confirm the absence of severe myocardial damage by the experimental preparation. Therefore, the possibility that severe hypoxic or mechanical injury to the myocardium at the time of isolation of rat hearts contributed to the altered hemodynamic responses to colforsin and adrenaline in the severe acidosis groups cannot be ruled out. However, similar hemodynamics ( $\mathrm{LV} \mathrm{dP/dtmax} \mathrm{and} \mathrm{CBF)} \mathrm{before} \mathrm{the} \mathrm{pH}$ change among the three groups as well as stable time control preparations do not support the presence of severe myocardial damage in our preparation.

In conclusion, $10^{-5} \mathrm{M}$ colforsin increased the LV contractility of isolated Langendorff rat hearts at $\mathrm{pH} 6.6$ to a level similar to that at $\mathrm{pH} 7.4$, whereas $10^{-6} \mathrm{M}$ adrenaline did not produce cardiac contractility similar to the physiological level. As opposed to currently available cardiotonic drugs, increasing dose of colforsin restored depressed cardiotonic effect induced by severe acidosis without increasing the incidence of ventricular arrhythmia. Thus, colforsin may be considered as an inotropic agent of choice when severe acidosis limits hemodynamic management in clinical settings. 


\section{References}

1. Fabiato A, Fabiato F: Effects of $\mathrm{pH}$ on the myofilaments and the sarcoplasmic reticulum of skinned cells from cardiac and skeletal muscles. J Physiol 276:233-55, 1978

2. Mattiazzi AR, Cingolani HE, de Castuma ES: Relationship between calcium and hydrogen ions in heart muscle. Am J Physiol 237:497-503, 1979

3. Blanchard EM, Solaro RJ: Inhibition of the activation and troponin calcium binding of dog cardiac myofibrils by acidic pH. Circ Res 55:382-91, 1984

4. Marban E, Kusuoka $\mathrm{H}$ : Maximal $\mathrm{Ca}^{2+}$-activated force and myofilament $\mathrm{Ca}^{2+}$ sensitivity in intact mammalian hearts: differential effects of inorganic phosphate and hydrogen ions. J Gen Physiol. 90:609-23, 1987

5. Watters TA, Wendland MF, Parmley WW, et al: Factors influencing myocardial response to metabolic acidosis in isolated rat hearts. Am J Physiol. 253:1261-70, 1987

6. Orchard $\mathrm{CH}$, Hamilton DL, Astles P, et al: The effect of acidosis on the relationship between $\mathrm{Ca}^{2+}$ and force in isolated ferret cardiac muscle. J Physiol. 436:559-78, 1991

7. Nakanishi T, Okuda H, Kamata K, et al: Influence of acidosis on inotropic effect of catecholamines in newborn rabbit hearts. Am J Physiol. 253:1441-8, 1987

8. Marsh JD, Margolis TI, Kim D: Mechanism of diminished contractile response to catecholamines during acidosis. Am J Physiol. 254:20-7, 1988

9. Modest VE, Butterworth JF: Effect of $\mathrm{pH}$ and lidocaine on beta-adrenergic receptor binding. Chest. 108:1373-9, 1995

10. Huang YG, Wong KC, Yip WH, et al: Cardiovascular responses to graded doses of three catecholamines during lactic and hydrochloric acidosis in dogs. $\mathrm{Br} \mathrm{J}$ Anaesth. 74:583-90, 1995 
11. Nimmo AJ, Than $\mathrm{N}$, Orchard $\mathrm{CH}$, et al: The effect of acidosis on beta-adrenergic receptors in ferret cardiac muscle. Exp Physiol. 78:95-103, 1993

12. Tanaka M, Ishikawa T, Nishikawa T, et al: Influence of acidosis on cardiotonic effects of milrinone. Anesthesiology. 88:725-34, 1998

13. Balnave CD, Vaughan-Jones RD: Effect of intracellular $\mathrm{pH}$ on spontaneous $\mathrm{Ca}^{2+}$ sparks in rat ventricular myocytes. J Physiol. 528:25-37, 2000

14. Mori M, Takeuchi M, Takaoka H, et al: Effect of NKH477, a new water-soluble forskolin derivative, on arterial-ventricular coupling and mechanical energy transduction in patients with left ventricular systolic dysfunction: comparison with dobutamine. J Cardiovasc Pharmacol. 24:310-6, 1994

15. Latini R, Zuanetti G, Conforti L, et al: Demonstration of a different sensitivity to epinephrine in isolated and in vivo hearts. Eur J Pharmacol. 156:87-94, 1988

16. Hirasawa A, Awaji T, Hosono M, et al: Effects of a new forskolin derivative, NKH477, on canine ventricular arrhythmia models. J Cardiovas Pharmacol. 22:847-51, 1993

17. Kikura M, Morita K, Sato S: Pharmacokinetics and a simulation model of colforsin daropate, new forskolin derivative inotropic vasodilator, in patients undergoing coronary artery bypass grafting. Pharmacol Res. 49:275-81, 2004

18. Hosono M, Takahira T, Fujita A, et al: Cardiovascular and adenylate cyclase stimulant properties of NKH477, a novel water-soluble forskolin derivative. J Cardiovas Pharmacol. 19:625-34, 1992

19. Hayashida N, Chihara S, Tayama E, et al: Effects of colforsin daropate hydrochloride in patients undergoing coronary artery bypass surgery (in Japanese). Kyobu Geka. 54:391-5, 2001

Page 18 of 23 
20. Poole-Wilson PA, Langer GA: Effects of acidosis on mechanical function and $\mathrm{Ca}^{2+}$ exchange in rabbit myocardium. Am J Physiol. 236:525-33, 1979

21. Williamson JR, Safer B, Rich T, et al: Effects of acidosis on myocardial contractility and metabolism. Acta Med Scand. 587:95-112, 1976

22. St. Louis PJ, Sulakhe PV: Adenosine triphosphate-dependent calcium binding and accumulation by guinea pig cardiac sarcolemma. Can J Biochem. 54:946-56, 1976

23. Kikura M, Morita K, Sato S: Pharmacokinetics and a simulation model of colforsin daropate, new forskolin derivative inotropic vasodilator, in patients undergoing coronary artery bypass grafting. Pharmacol Res. 49:275-81, 2004

24. Toya Y, Schwencke C, Ishikawa Y: Forskolin derivatives with increased selectivity for cardiac adenylyl cyclase. J Mol Cell Cardiol. 30:97-108, 1998

25. Hirota K, Yoshioka H, Kabara S, et al: Spasmolytic effects of colforsin daropate on serotonin-induced pulmonary hypertension and bronchoconstriction in dogs. Acta Anaesthesiol Scand. 46:297-302, 2002

26. Tanahashi M, Hara S, Yoshida M, et al: Effects of NKH477 on renal functions and cyclic AMP production in anesthetized dogs. Eur J Pharmacol. 372:253-9, 1999

27. Neda K, Handa J, Onikata S, et al: A Single Dose Toxicity Study of Colforsin dapropate hydrochloride(NKH477) in Rats and Dogs (in Japanese). Oyo Yakuri. 49:635-41, 1995

28. Kimura H, Fujimura T, Nakagawa K, et al: A 13-week Intravenous Toxicity Study of Colforsin dapropate hydrochloride(NKH477) in Rats, Followed by a 5-week Recovery Test (in Japanese). Oyo Yakuri. 49:643-69, 1995 
29. Maeda Y, Yamasaki K, Shiraishi K, et al: A 13-week Intravenous Toxicity Study of Colforsin dapropate hydrochloride (NKH477) in Dogs, followed by a 5-week recovery test (in Japanese). Oyo Yakuri. 49:671-92, 1995

Page 20 of 23 


\section{Figure legends}

Figure 1: Experimental protocols for measuring hemodynamics (Experiment 1) and tissue cAMP contents (Experiment 2) with or without colforsin or adrenaline at $\mathrm{pH}$ 7.4, 7.0 and 6.6.

Figure 2: Temporal changes in left ventricular pressure and left ventricular $\mathrm{dP} / \mathrm{dtmax}$ of a typical representative heart, showing depressions in these variables after introduction of $\mathrm{pH}$ 6.6 and enhancement of these variables by escalating doses of colforsin. Note that peak and stable responses are obtained within $10 \mathrm{~min}$ after initiation of a new $\mathrm{pH}$ as well as three concentrations of colforsin.

Figure 3: Changes in left ventricular $\mathrm{dP} / \mathrm{dt} \max (\mathrm{LV} \mathrm{dP} / \mathrm{dtmax}$ ) without colforsin or adrenaline at $\mathrm{pH}$ 7.4, 7.0 and 6.6. Data are shown as means $\pm \mathrm{SD}$ ( $\mathrm{n}=6$ each). $\mathrm{LV} \mathrm{dP/dtmax}$ significantly decreased with $\mathrm{pH}$ change in the mild and severe acidosis groups, and remained depressed throughout the experiment. $\mathrm{LV} \mathrm{dP} / \mathrm{dtmax}$ values at each $\mathrm{pH}$ were essentially unchanged over time after $\mathrm{pH}$ change. ${ }^{*} \mathrm{P}<0.05$ vs. pre-pH change.

Figure 4: Changes in left ventricular $\mathrm{dP} / \mathrm{dtmax}(\mathrm{LV} \mathrm{dP} / \mathrm{dtmax}$ ) with or without colforsin at $\mathrm{pH}$ 7.4, 7.0 and 6.6. Data are shown as means $\pm \mathrm{SD}$ ( $\mathrm{n}=8$ each). $\mathrm{LV} \mathrm{dP} / \mathrm{dtmax}$ decreased with $\mathrm{pH}$ change in the mild and severe acidosis groups. Colforsin significantly increased $\mathrm{dP} / \mathrm{dtmax}$ in all groups at $10^{-6} \mathrm{M}$ and $10^{-5} \mathrm{M} . * P<0.05$ vs. pre-pH change. ${ }^{\dagger} P<0.05$ vs. post-pH change and time (vehicle) control values at corresponding $\mathrm{pH}$ (Figure 3). $\$ \mathrm{P}<0.05 \mathrm{vs}$. control (pH 7.4) group. No significant difference was found among the three groups at colforsin $10^{-5}$. 
Figure 5: Changes in coronary perfusion flow (CPF) with or without colforsin at pH 7.4, 7.0 and 6.6. Data are shown as means $\pm \mathrm{SD}$ ( $\mathrm{n}=8$ each). Change in $\mathrm{pH}$ decreased $\mathrm{CPF}$ in the severe acidosis group. Colforsin significantly increased CPF in all group at all concentrations compared with the post-pH change and the time control values (data not shown). $* P<0.05$ vs. pre-pH change. ${ }^{\dagger} P<0.05$ vs. post-pH change and time (vehicle) control values at corresponding $\mathrm{pH}$. No significant difference was found among the three groups.

Figure 6: Changes in left ventricular $\mathrm{dP} / \mathrm{dtmax}$ ( $\mathrm{LV} \mathrm{dP/dtmax)} \mathrm{with} \mathrm{or} \mathrm{without} \mathrm{adrenaline} \mathrm{at}$ $\mathrm{pH}$ 7.4, 7.0 and 6.6. Data are shown as means $\pm \mathrm{SD}$ ( $\mathrm{n}=8$ each). LV dP/dtmax decreased with $\mathrm{pH}$ change in the mild and severe acidosis groups. Adrenaline significantly increased $\mathrm{dP} / \mathrm{dtmax}$ in control and mild acidosis groups at $10^{-7} \mathrm{M}$ and in all groups at $10^{-6} \mathrm{M} . * \mathrm{P}<0.05$ vs. pre-pH change. ${ }^{\dagger} \mathrm{P}<0.05$ vs. post-pH change and time (vehicle) control values at corresponding $\mathrm{pH}$ (Figure 3). $\$ P<0.05$ vs. control ( $\mathrm{pH}$ 7.4) group. Although LV dP/dtmax significantly increased with $10^{-6} \mathrm{M}$ adrenaline in the severe acidosis group, it was significantly less than that of the control group.

Figure 7: Changes in coronary perfusion flow (CPF) with or without adrenaline at $\mathrm{pH} 7.4$, 7.0 and 6.6. Data are shown as means $\pm \mathrm{SD}$ ( $\mathrm{n}=8$ each). Change in $\mathrm{pH}$ decreased CPF in severe acidosis group. Adrenaline significantly increased CPF in the control and mild acidosis groups at all concentrations studied, but not in the severe acidosis group. ${ }^{*} P<0.05$ vs. pre-pH change. ${ }^{\dagger} \mathrm{P}<0.05$ vs. post-pH change and time (vehicle) control values at corresponding $\mathrm{pH}$. 
Figure 8: Cyclic adenosine monophosphate (cAMP) contents in isolated left ventricular muscles perfused with or without colforsin or adrenaline at pH 7.4 and 6.6. Data are shown as means \pm SD ( $n=6$ each). Colforsin or adrenaline was given in the identical sequence as the experiment 1 (Figure 1). Decrease in $\mathrm{pH}$ from 7.4 to 6.6 resulted in significantly less cAMP without cardiotonic drugs. Colforsin significantly increased cAMP contents at pH 7.4 and 6.6. Similarly, adrenaline also increased cAMP contents both at $\mathrm{pH} 7.4$ and 6.6, but resulted in significant difference between $\mathrm{pH} 7.4$ and 6.6 after $10^{-6} \mathrm{M}$ adrenaline. ${ }^{*} \mathrm{P}<0.05$ between $\mathrm{pH}$ 7.4 and 6.6. ${ }^{\dagger} \mathrm{P}<0.05$ vs. without colforsin or adrenaline at corresponding $\mathrm{pH}$. 
Fig. 1

Experiment 1

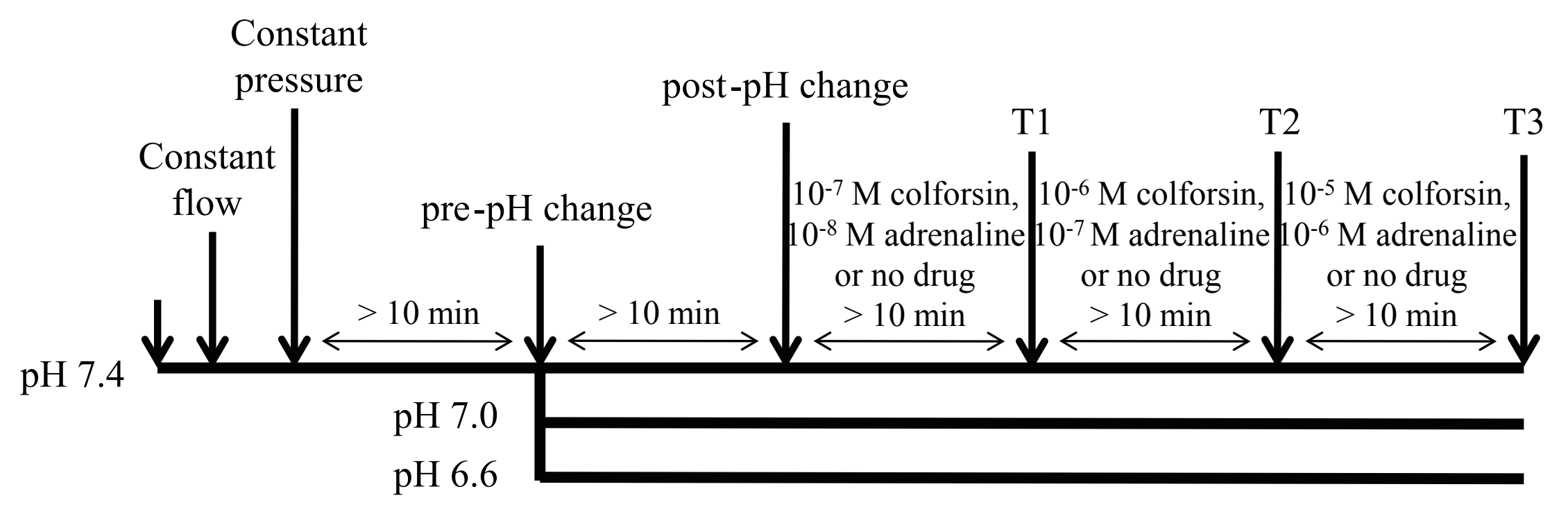

Experiment 2

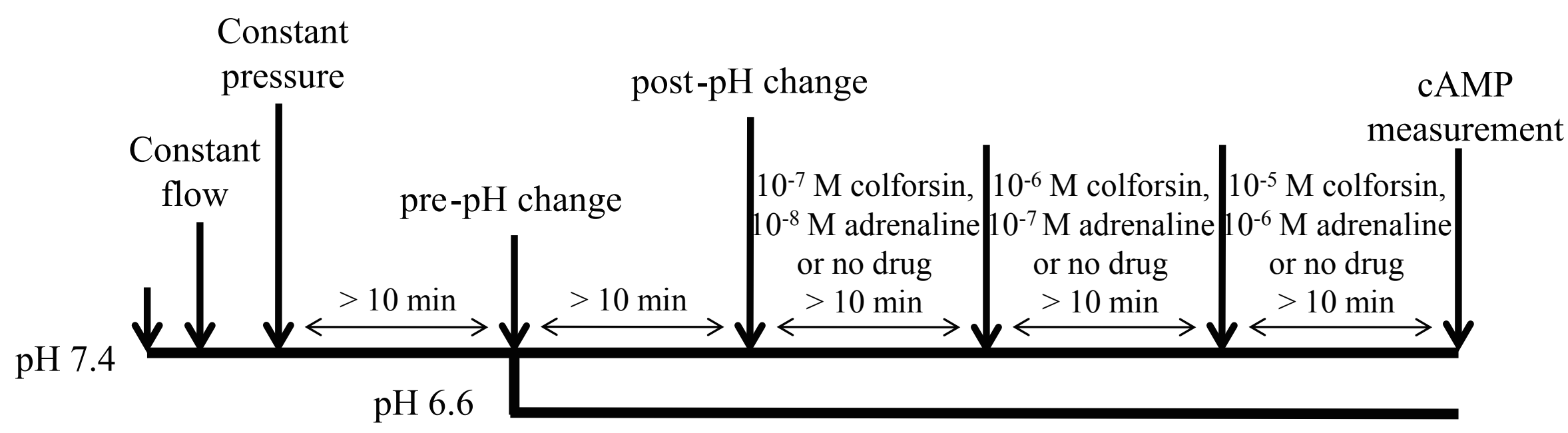


Fig. 2
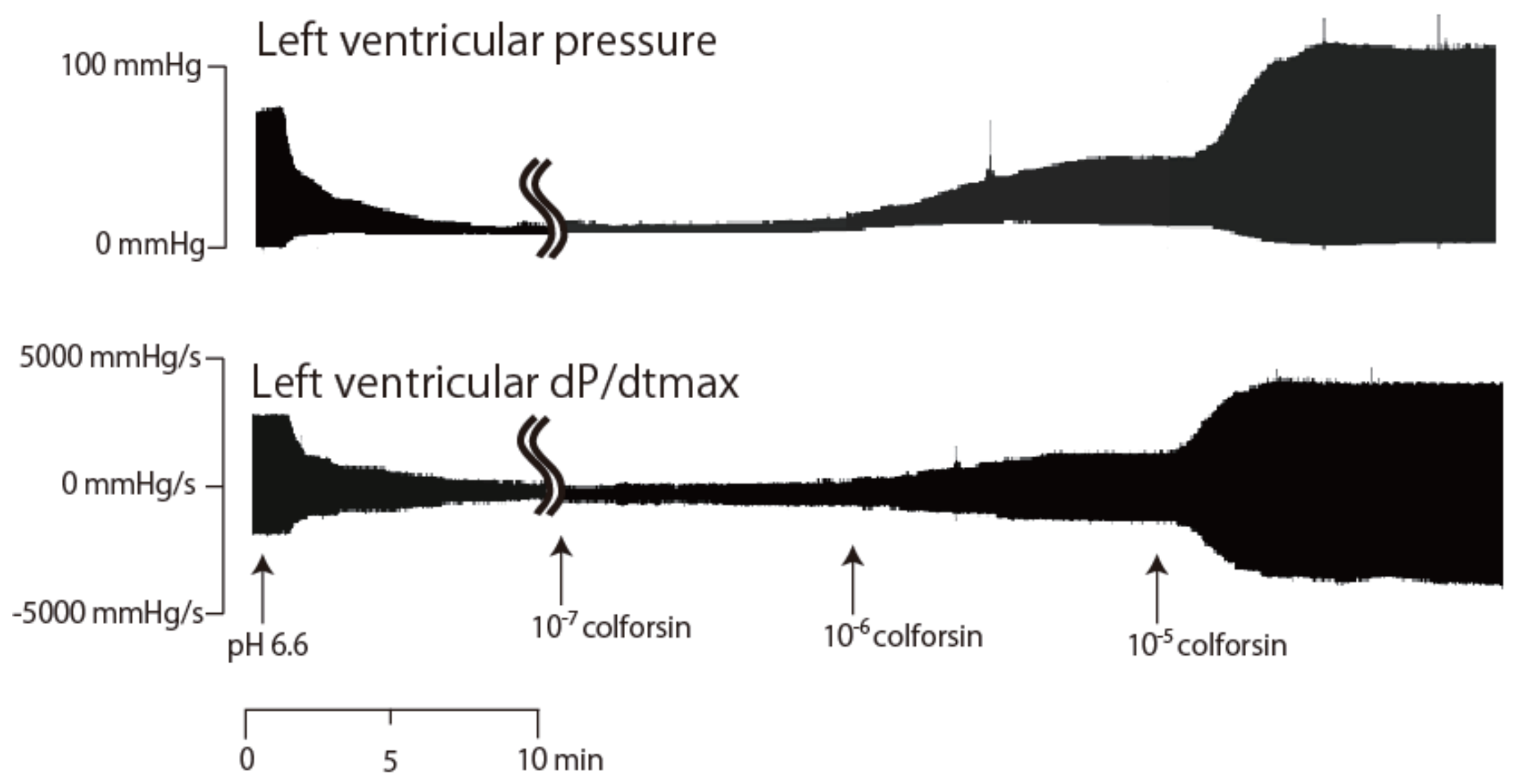
Fig. 3

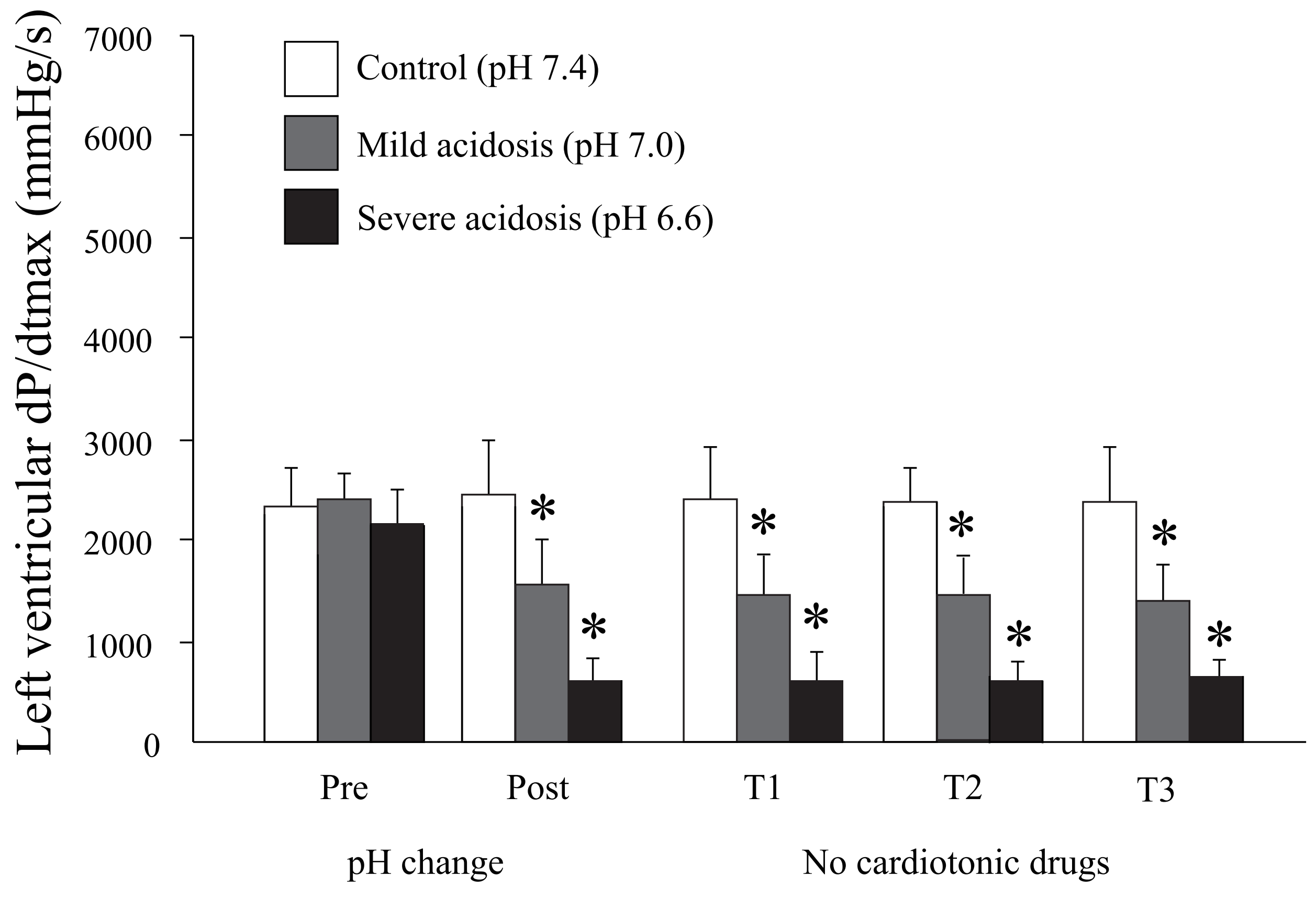


Fig. 4

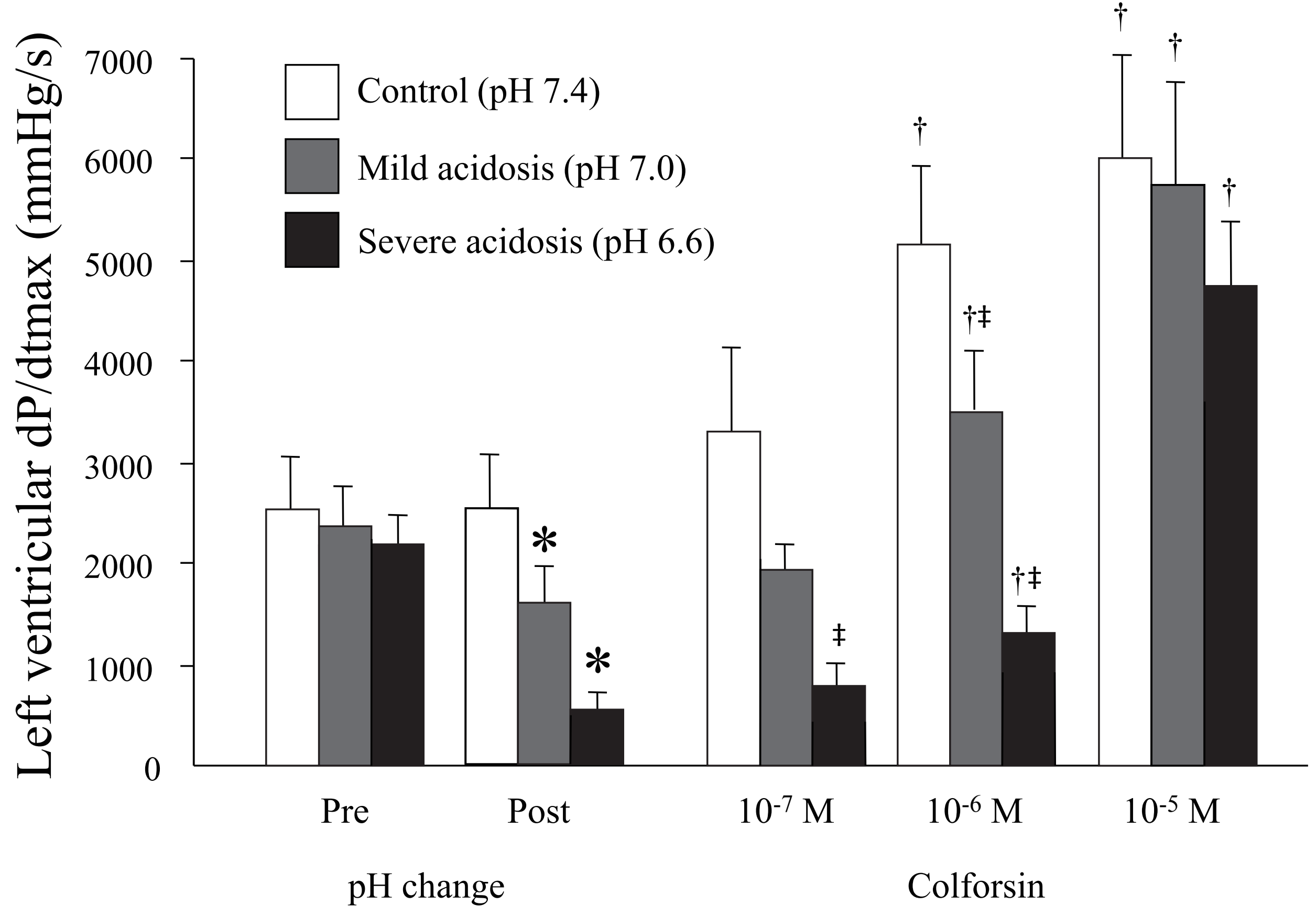


Fig. 5

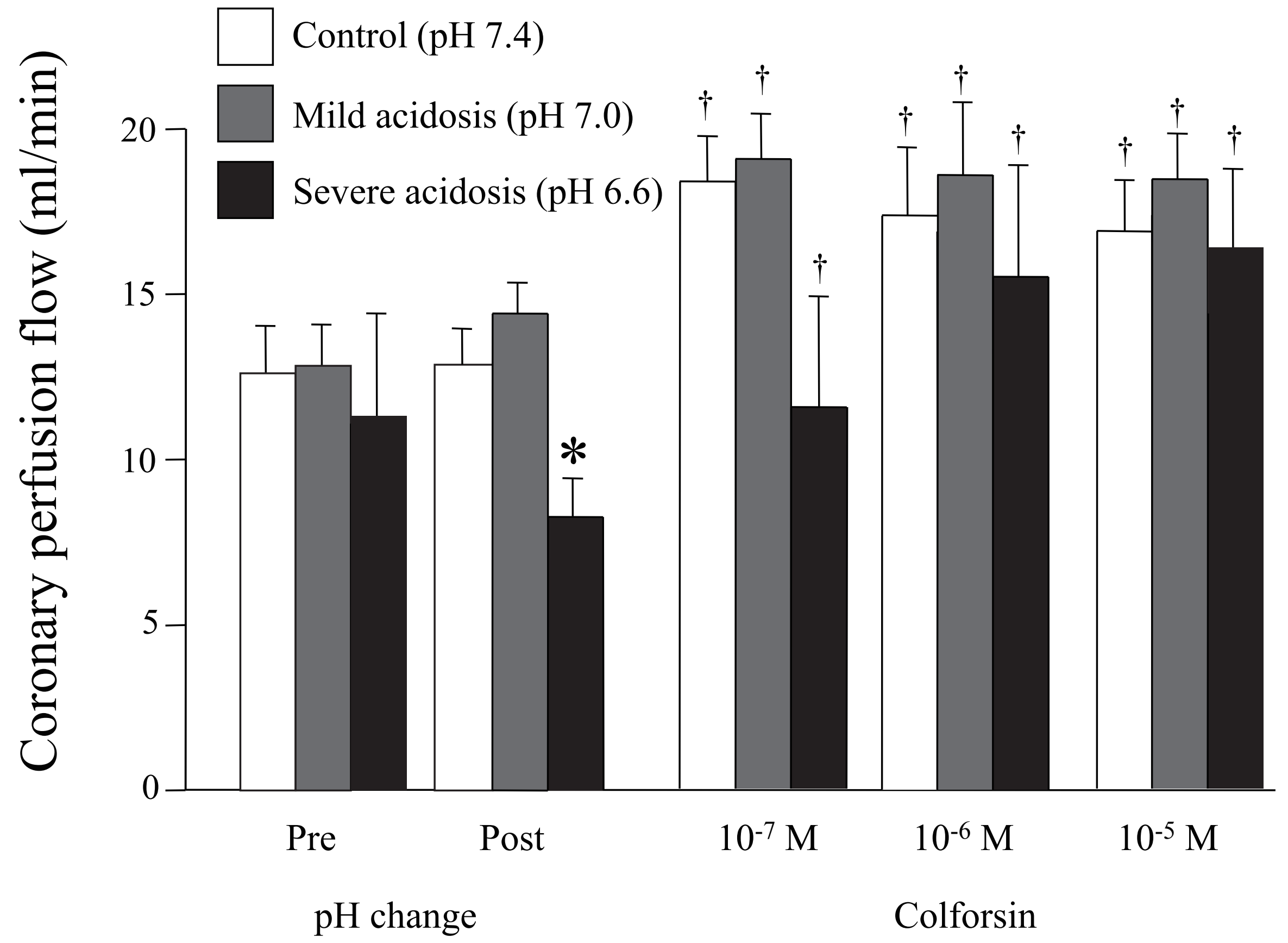


Fig. 6

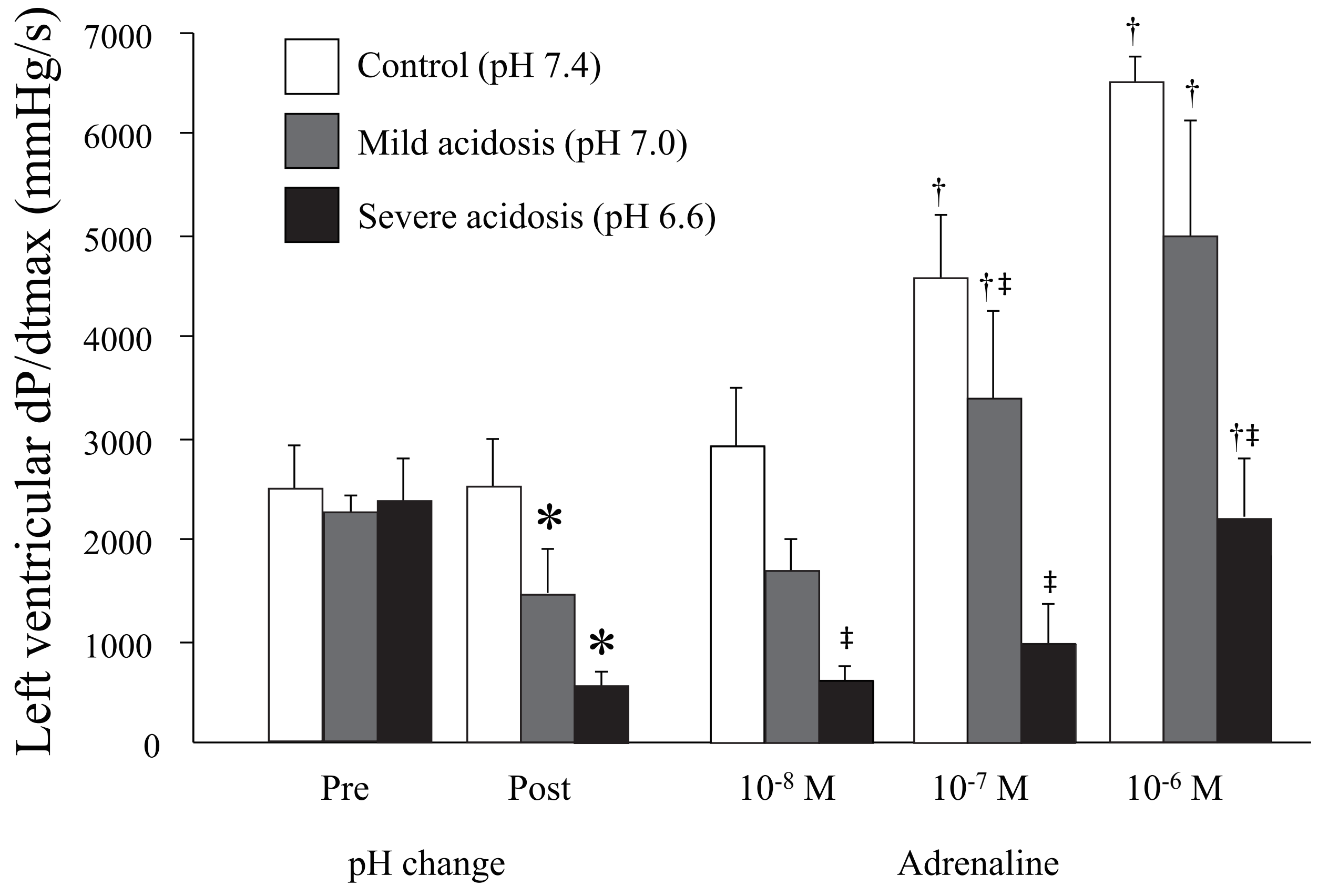


Fig. 7

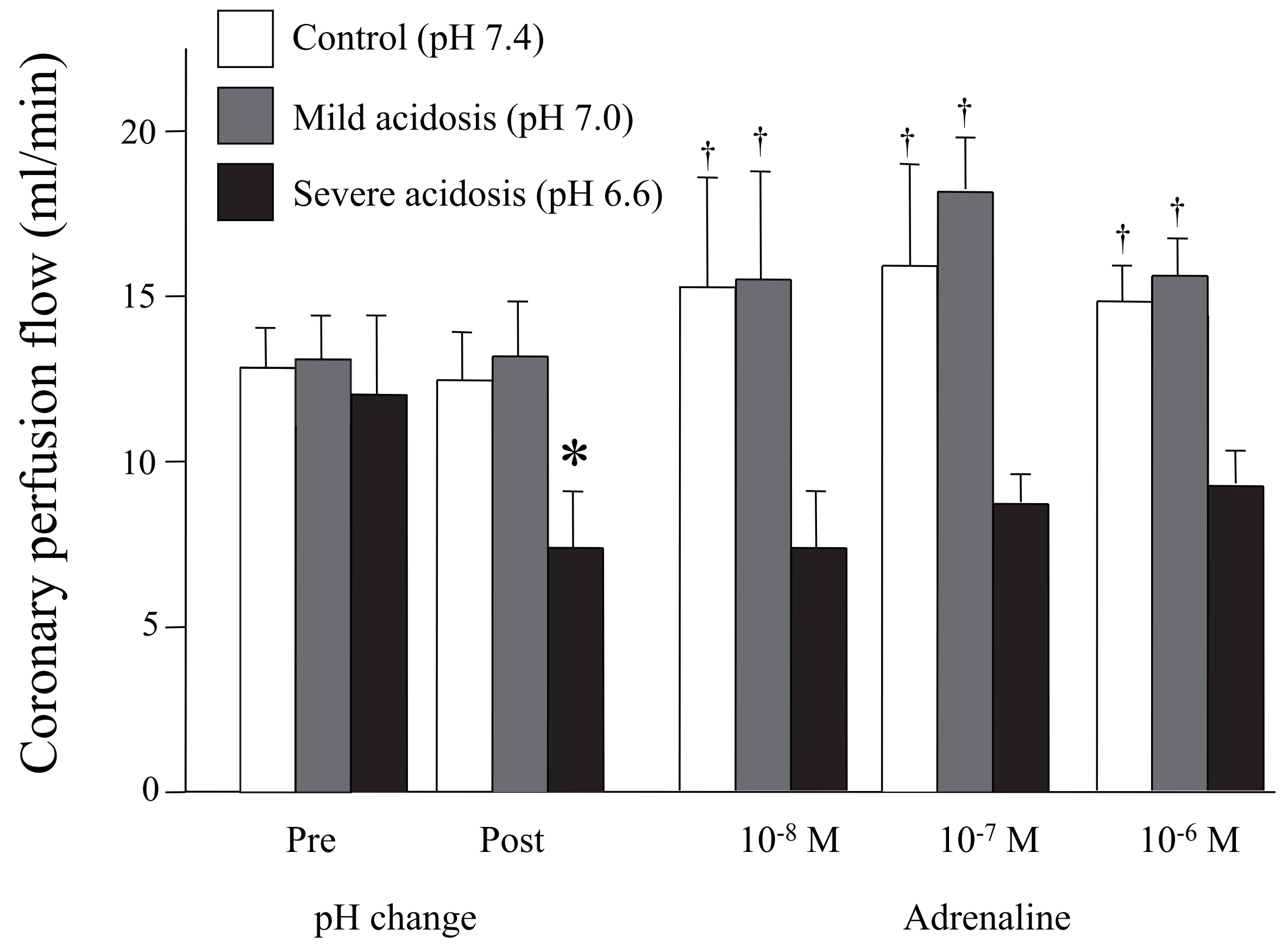


Fig. 8

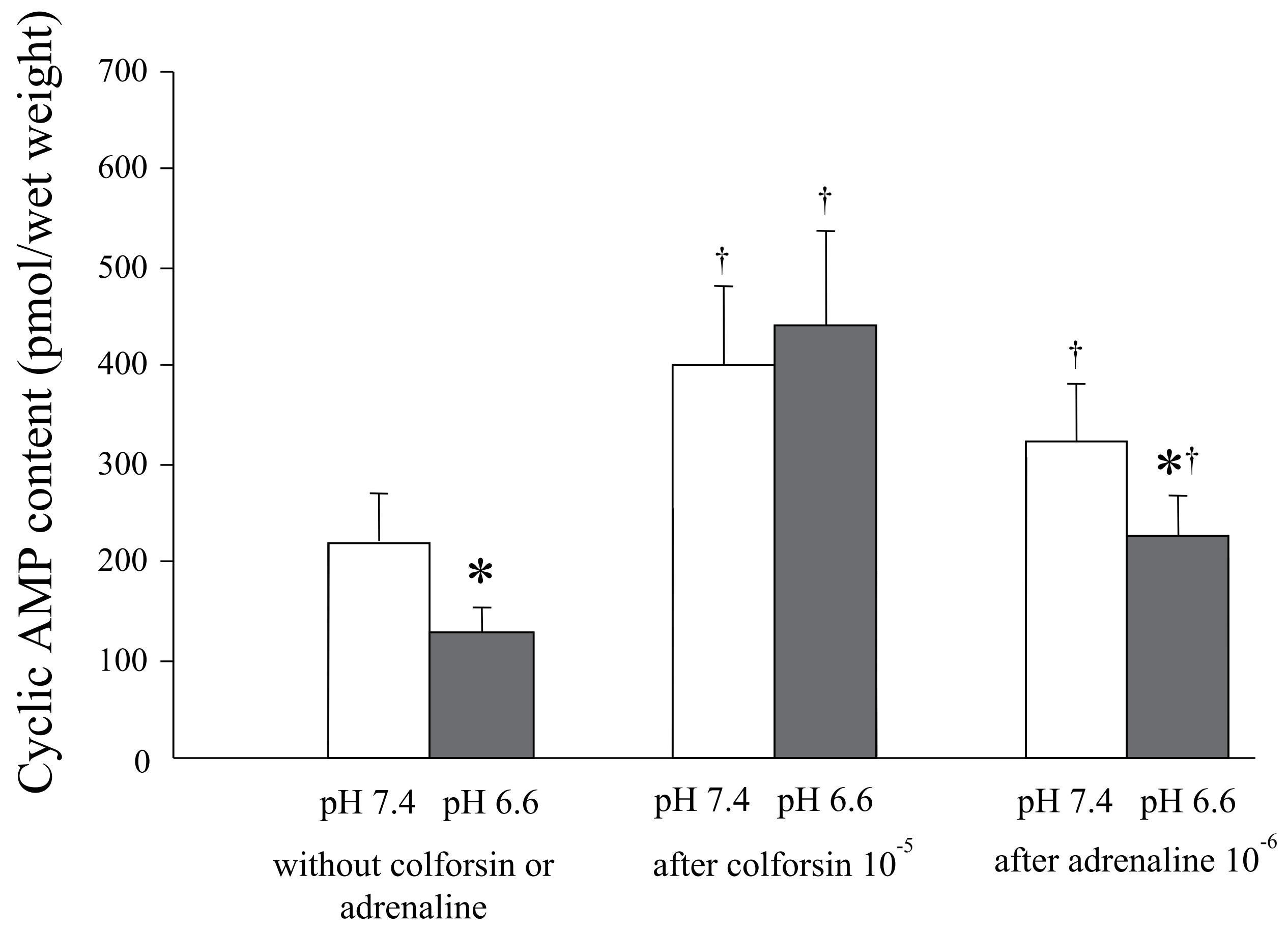

